\title{
A Diary-Based, Cross-Contextual Case Study Methodology: Background for the Case of "Jane and Joe"
}

\author{
THOMAS MACKRILL ${ }^{\text {a,b }}$ \\ ${ }^{\mathrm{a}}$ University of Aarhus, Aarhus, Denmark \\ Correspondence concerning this article should be addressed to Thomas Mackrill, Æblehaven 2, 3450 Allerød, \\ Denmark. \\ Email: thomas@life-change.dk
}

\begin{abstract}
This paper describes the epistemological, theoretical, and methodological background and context of the therapy case study, "The Case of 'Jane and Joe': A Diary-Based, Cross-Contextual Case Study," published in this journal (Mackrill, 2011). The "Jane and Joe” case study served as the "raw data" of a "jury trial model" analysis, also published in this journal by Bohart, Tallman, Byock, and Mackrill (2011). The Joe and Jane case study is one of eight researched as a series with a method inspired by postmodern-oriented movements in phenomenology, post-positivism, hermeneutics, social constructionism, and action research. Specifically, the method used in analyzing the Jane and Joe case study involved the client (Jane) and therapist (Joe) following a set of diary writing guidelines for a series of 10 therapy sessions, which were audio-recorded. The therapist wrote about his experience of the sessions, and the client wrote both about her experience of the sessions, and about her new and different experiences between sessions. After the 10 sessions were competed, Joe and Jane exchanged diaries at the end of the eleventh session, and the twelfth session was dedicated to responding to the experience of reading each other's diaries. The diaries and recordings were then passed on to me as the researcher for analysis. My draft analysis of the Jane and Joe case study was next sent to Jane and Joe for comment so misinterpretations could be corrected. Jane and Joe's amendments were then incorporated into the final case study, which is published in this journal (Mackrill, 2011). The analysis of the audio recordings and the diaries followed a systematic series of procedures within a particular theoretical framework. The framework has three major dimensions: (a) a postmodern emphasis on the patient and therapist's experiences and phenomenology as they dynamically interact with one another (McLeod, 2010); (b) a postmodern emphasis on the development of the client's sense of agency during the therapeutic process; and (c) in line with Dreier's (2008) theory of cross-contextual influences, an emphasis on the importance of cross-contextual transactions between the client's experience inside and outside of therapy during the time of the therapy.
\end{abstract}

Key words: psychotherapy, counseling, diaries, adult children, everyday life, cross-context theory, phenomenology, sense of agency, case studies, clinical case studies 


\section{EPISTEMOLOGICAL AND THEORETICAL BACKGROUND}

Denzin and Lincoln (1994a, 1994b, 2005a, 2005b) analyzed methods in qualitative research and proposed that over time there has been a series of "moments" in qualitative research that reflect differing epistemological stances. Reflecting on these, Seale (1999, p. 472) highlighted the importance of a pluralistic approach to qualitative research noting "practicing social researchers can learn to do good work from a variety of examples, done within different 'moments' without needing to resolve methodological disputes before beginning their work." Support for the notion of epistemological pluralism in qualitative psychotherapy research can be found in McLeod (2001), who applies Denzin and Lincoln's (1994a, 1994b) analysis of moments of development in qualitative research to the field of psychotherapy research. McLeod (2001) draws the conclusion that qualitative psychotherapy research is still in the modernist phase, where methods are formalized and presented as recipes of what to do. Denzin and Lincoln (1994a, 2005a) refer to the moment that follows the modernist moment as "the blurring of genres," where researchers draw on "a broad repertoire of paradigms, methods, strategies and techniques" (Denzin \& Lincoln 2005a, p.17). After this, Denzin and Lincoln (1994b) refer to other moments, such as a "fifth moment," which involves a pluralistic, more action-oriented and political approach to qualitative research.

The present Jane and Joe case study is in line with Denzin and Lincoln's fifth moment. Specifically, the way of connecting research design to the object of study in the design presented here differs significantly from research within the modernist framework. The modernist assesses the object of study to determine which of the variety of "proper," established methods is most appropriate. The present study, however, is built on the premise that various scientific methods enable the scientist to grapple with differing objects of study, differing research questions, within the concrete possibilities of different specific research projects. The epistemological position taken here involves viewing the object of study - in this instance, the inner experiences, behaviors, and life contexts of an interacting client and therapist during 10 weeks of therapy-as the key determinant of how paradigms, methods, strategies, techniques, and theory are combined in the design of the individual research project. The case study method presented here is thus the work of what Denzin and Lincoln (1994a, 1994b, 2005a, 2005b) call a qualitative, pragmatically oriented "bricoleur.” Denzin and Lincoln (1994a, 1994b, 2005a, 2005b) and McLeod (2001) employ the term "bricolage" to describe the craft of the modern qualitative researcher, and the term "bricoleur” to describe the qualitative craftsman. In Denzin and Lincoln's words, (1994a, p.3, "The bricoleur produces a bricolage, that is, a pieced-together, close-knit set of practices that provide solutions to a problem in a concrete situation.” The choice of practices depends on the research question, the object of study, and what is practically possible. With this in mind, it is important to note that the method created and presented in this study was developed specifically to study psychotherapy as cross-contextual practice.

The concept of cross-contextual practice has been developed in the work of Dreier (1998, 2008), who views psychotherapy as a complex, ongoing, cross-contextual phenomenon. Typically, psychotherapy research attributes outcome to the therapeutic intervention and/or the actions of the therapist. On the one hand, this makes complete sense, as most psychotherapy researchers are interested in the effects of interventions. On the other hand, such an attribution makes little sense, as psychotherapy clients are not simply passive recipients of interventions. 
What occurs in sessions always transpires within the wider context of the client's life. We cannot presume that psychotherapy sessions are the only arena in which the client undertakes activities with regard to resolving their troubles. The client's psychotherapeutic practice typically starts prior to the first session when the client is troubled and begins to consider psychotherapy as an option. The ongoing everyday lives of clients' between sessions cannot be presumed solely to be an arena of therapeutic outcome or part of an action stage of therapy (Hill, 2004). Nor can we presume to interpret what occurs in the client's everyday life merely as a set of bonus factors that aid or inhibit the intervention.

What occurs in the client's life before, between, and after sessions may well be an integral part of the therapeutic process as a whole, as argued by Dreier (2008). If Dreier (2008) is correct, researchers aiming to understand the processes and outcomes of psychotherapy would need to gather data about the client's changing life as a whole, where psychotherapeutic interventions are but one part of this life. Focusing on the links between the various contexts in the client's life (including therapy sessions) would be important. Yin (2003), a key proponent of case studies, argues "a case study is an empirical inquiry that investigates a contemporary phenomenon within its real-life context, especially when the boundaries between phenomenon and context are not clearly evident” (p.13). With regard to psychotherapy practice, the boundaries between the phenomenon and its contexts are seriously blurred. This is a central reason why psychotherapy research lends itself to qualitative case studies.

Studying psychotherapy as a cross-contextual practice requires data both about sessions and about the client's life outside sessions, and a method of analyzing the data that draws attention to the relationship between what occurs in sessions and in the other contexts of the client's life. Dreier (2008) had this same theoretical agenda. He employed a labor intensive method that involved analyzing 26 sessions of therapy with a family of four and 11 interviews with various family members about their everyday lives between sessions and the significance of sessions for their lives. Dreier (2008) analyzed transcripts of this data and showed in detail the impact of extra-therapy experiences and events upon a client's life-both independently of therapy, and in reciprocal interaction with therapy. While it has similar epistemological and theoretical aims, the diary-based case study method presented here is far less labor intensive than Dreier's approach. No transcripts or interviews are required.

\section{THE PROJECT'S HISTORY}

The research project from which the Jane and Joe case study came was my Ph.D. dissertation and started while I was employed as a therapist at a counseling service for young adults from families with alcohol problems in Denmark. I first carried out a pilot diary study of 10 sessions using a preliminary set of diary guidelines, where I was the therapist. The guidelines were then revised, and I began to collect data from some of my colleagues. Once funding for the research project was secured, I spent six months developing a method of diary analysis, to be described below. As also described below, three cases were analyzed in addition to the Jane and Joe case focused on here.

One of the case analyses - that of Jane and Joe-is presented in its full length here (Mackrill, 2011). Following the completion of my dissertation, I wrote a series six articles based 
on this work. One article (Mackrill, 2008a) reviews previous qualitative diary studies of psychotherapy and investigated arguments for and against the employment of solicited diaries studies in qualitative psychotherapy research. A second article (Mackrill, 2007) presents the diary design employed in this study. A third article (Mackrill, 2009a) examined how the view of client agency presented in this study and Dreier’s (2008) differs from other psychotherapy research constructions of client agency. A fourth article (Mackrill, 2008b) examines how leaving home appears to be significant to the psychotherapy processes of all four clients studied. A fifth article (Mackrill, 2008c) examines the significance of the clients' independent strategies for change while in therapy and the interplay between the clients' strategies for change and the therapists' responses. This article suggested that clients' independent strategies for change may be a significant factor with regard to therapeutic processes and outcomes. A sixth article (Mackrill, 2009b) presents data about the clients' use of extra-therapeutic factors. Six types of extra-therapeutic information sources that clients used to develop their personal stances while in therapy were identified. None of the full-length cases have been published previously.

\section{THE DIARY METHOD}

Diary methods seemed highly suited to the study of psychotherapy for a series of reasons. Diaries have traditionally been used to support and report self-development (Alaszewski, 2006, p.10; Symes, 1999 p.360). Diaries can access data about clients' changes in state. Having both clients and therapists keep diaries seemed an achievable way of accessing the therapeutic relationship, offering the possibility of comparing perspectives. Asking therapists to focus on their concerns in sessions seemed an appropriate way of gathering data about therapist strategies, both in terms of specific intervention techniques and the development and dynamics of the therapeutic relationship. The fact that diaries involve intermittent self-reporting corresponded to the temporally intermittent nature of therapeutic practice, where clients come to a series of sessions. Finally, diary methods offered a way of granting access to the contexts of clients' everyday lives, as well as to sessions. Given that diary methods seemed appropriate in relation to so many of psychotherapy's central components, it seemed surprising that diary methods have been relatively absent within qualitative psychotherapy research.

Diaries do appear in the world of therapy. Cognitive-behavior therapy has long employed diaries as a therapeutic method, e.g., for monitoring therapeutic "homework" between sessions and for exposure purpose in the treatment of PTSD (e.g., Resick, Monson, \& Rizvi, 2008). For a review of diaries as a form of intervention and intervention support see Levine \& Calvanio (2007).

Although there are many quantitative studies that employ diary methods (for a review, see Thiele et al., 2002), a search for qualitative diary methods revealed but four references. Rogers (1951) and Evans and Robinson (1978) have published extracts from clients' unsolicited diaries about their experiences of psychotherapy. The diaries are presented verbatim with comments but with no systematic analysis or methodological reflections. Existential psychiatrist Irving Yalom solicited a diary from his client, who is given the pseudonym, "Ginny Elkin," while keeping a diary himself. These diaries have been jointly published (Yalom \& Elkin, 1974). The dual perspective is presented as an exercise in self-disclosure, but the publication provides no systematic analysis of the diaries. Wosket (1999) carried out the fourth diary study, also with 
a dual perspective, where she was the therapist. The diaries were guided by a series of incomplete sentences concerning significant aspects of sessions, helpful/unhelpful events, unfulfilled wishes in sessions, the therapeutic relationship, and themes in the session. The other diary studies merely present diary data verbatim, and Wosket presented descriptive summaries of the diaries related to the five themes. Thus, in all five studies, there was a reluctance to interpret the data. Interestingly, one of the themes Wosket summarizes is entitled "extratherapeutic factors occurring at the boundaries of the counseling work" (1999, p. 89), revealing that diaries offer access to the contexts of clients' everyday lives.

In contrast to the above studies, which were reluctant to analyze and interpret diary data, this project aimed to draw on one of the strengths of diary methods and create a particular crosscontextual, theoretical view of psychotherapeutic practice by gathering data both from sessions and from the other contexts in the client's lives prospectively. The design involved a set of guidelines for therapist and clients, a set of analytic procedures, a theory-driven analysis, and a series of validation procedures. The approach did not aim to create a "saturated" theory, a "thick description," or an exhaustive review of all possible interpretations of the data. The approach aimed to construct a particular view of practice. The approach involved a series of procedures to avoid perspectives other than the one driven by Dreier's cross-contextual theory of therapeutic practice. The design was thus built on the premise that scientific results are constructed through a series of methodological assumptions and strategies, or what Law (2004) called "assemblages," and that scientific results can best be assessed by making these assemblages explicit. According to the understanding employed here, all scientific methods construct particular views. The methodological assemblages involved in randomized controlled trials, for example, also construct a particular view of psychotherapeutic practice by employing particular methodological assemblages while taking steps to avoid other interpretations. This article reflects on how the methodological assemblages employed in this study constructed psychotherapy as a crosscontextual practice. The study is exploratory, and as such, the design, including the theory, was developed and refined during the course of the study.

\section{PARTICIPANTS AND SELECTION PROCEDURES}

This research project's design was developed to investigate professional counseling taking place at a Danish counseling service for young people who had grown up in families with alcohol related problems. The study involved the intensive study of a small number of cases. Eight sets of diaries were collected. Four cases were analyzed. These four cases involved three female clients and one male client. The clients were all students (though not of counseling or psychology) and in their twenties. Three therapists participated (two male, one female). Two of the therapists were university-educated psychologists. One was a privately trained psychotherapist. Two of the therapists had many years of experience. One had recently qualified for independent practice. While not a manualized form of treatment, the counseling was based on psychodynamic, humanistic, and existential concepts, principles, strategies, and procedures. I was the lone researcher: a university trained psychologist, eclectic but with existential phenomenological and structural leanings, and with ten years of counseling experience. As the project was a Ph.D. dissertation, a senior-level doctoral clinical psychology supervisor closely followed the project. 
Participation in the project was voluntary for both therapists and clients. Clients were informed in a written, informed consent document and also orally by the therapists that choosing not to participate in the study would not influence their access to therapy at the counseling service in any way. Clients were also informed that they could choose to withdraw from the project at any time, without this infringing on their possibilities for continued therapy. Apart for the obvious ethical reasons for such an arrangement, it also worked to enlist clients who were highly motivated with regard to keeping a diary. The informed consent document also emphasized the importance of being motivated to write and investigate, aiming to attract highly motivated clients as these were expected to write more (Sheridan, 1993 p.34; Coxon, 1996, p.20).

Being motivated and having an ability to reflect in writing were the key criteria for choosing which clients to ask to participate. Selecting highly motivated clients is thus a source of selectivity in this diary study. Specific issues concerning clients who lack motivation for treatment or clients who have difficulty putting their experiences into words were not addressed. Another criterion for clients was that they had to be able to read and understand an analysis of their case written in English, a foreign language, as all the clients were ethnic Danes. Most Danish students in higher education are quite proficient in English and are used to reading advanced texts in English, as many texts used in higher education are not translated into Danish. Another participation criterion was the requirement that participants write their diaries on their own computer in Microsoft's "Word” format. As far as the design was concerned, there was clearly a time saving aspect to this. The design did not involve transcribing hand-written diaries, interviews, or session recordings. The client and therapist diaries were the primary source of data. The therapists, rather than the researcher, selected the clients, who were offered the option of participating, as part of their referral and screening process. My phone number and email address were in the written consent form and the guidelines so both clients and counselors could contact me with queries.

Participants were informed that they would be viewed as co-researchers. The therapists were encouraged to reflect in their diaries about their therapeutic practice and their clients' everyday lives outside the therapy. Clients were encouraged to reflect about the significance for them of the psychotherapy sessions and to reflect about how they changed in their everyday lives. Meetings were held with the therapists about the logistical details of the project to discuss their queries and concerns. I did not actually meet the clients.

\section{DIARY-WRITING GUIDELINES AND DATA-GATHERING PROCEDURES}

To understand the way the study procedures were constructed, it is important to recall the aim of this study, which was to investigate the connection between what went on in sessions and what went in the client's life contexts outside sessions. Thus, the study needed access to two types of data: first data concerning the client's contexts in their everyday lives outside therapy; and second, data from therapy sessions. To secure quality data, diary-writing guidelines for therapists and clients were written and handed out to them. The guidelines emphasized the focus of the study and a question checklist was included. An English version of the client's and therapist's guidelines are presented in Appendices 1 and 2, respectively. (The English in the 
Appendix was grammatically improved over the guidelines given to the clients, but the substance of the guidelines was not changed.) Gaining access to sessions was achieved using diary entries where clients and counselors recorded what they found significant in sessions and their thoughts about why they found particular aspects of sessions significant. Counselors were asked specifically how they thought significant events in sessions played a part in the client's life outside therapy. Clients and counselors were asked to write entries about sessions right after the sessions to restrict problems of recall and reinterpretation. The sessions were also audiorecorded.

Accessing data about clients' lives in contexts outside sessions relied mainly on the data in clients' diaries. Clients were encouraged to present details about their lives in places outside sessions by asking them to mentally go through the time that had elapsed since the previous session, considering where they had been and what they had done. Clients were asked to describe new and different aspects of their lives during this period. They were then asked to try and explain the occurrence of these new/different experiences. Finally, they were asked to look for possible connections between these new/different experiences and what occurred in the therapy sessions. The order of these questions was important. In Dreier's study (2008), the same sequence was used in a between-session interview guide regarding clients' everyday lives while in therapy. The sequence aimed to encourage clients to write about their everyday lives without immediately censoring what they wrote by considering the relevance of what they were writing for the process going on in the therapy sessions. As clients received the diary-writing guidelines from their therapist, I presumed they would have a tendency of thinking about the relevance of what they were writing for the therapist. The guidelines thus attempted to restrict this. Clients were encouraged to disregard counselor expectations by asking them to write all the new or different experiences down, however great or small they seemed. Varied examples were given in the guidelines of the type of data that might be expected, in an attempt to encourage this nonexplanatory, non-censoring, descriptive attitude when describing new and different experiences.

In the diary-writing guidelines, particular questions were given particular numbers and letters. However, most client diaries simply did not divide their diary into the number and letter structure that the guidelines employed. Some clients seemed to experience a conflict in the instructions between being encouraged to write freely and the numbered and lettered questions in the guidelines, which restricted their flow (Aleszewski, 2006, p.80). Interestingly, most chose to ignore the system that was imposed and wrote freely. A question was added to the client guidelines after the first two cases, whereby clients were asked when they had thought about the therapy sessions since the last session. Response to this question was extremely limited, suggesting that the question inhibited clients' flow excessively.

Placing clients in a tension between writing freely and following guidelines was central to the method. The design involved clients grasping the intentions behind the study and then writing as freely as possible. By asking too many questions, I risked limiting my data. In future studies I would not recommend using the added question, but I would maintain the letter and number system in the guidelines, as this helped clients focus on cross-contextual aspects of psychotherapeutic practice. Some clients expressed concern to therapists about the fact that they did not rigidly follow the guidelines. The counselors were instructed to be supportive and generally encourage them to write. 
Sessions at the counseling service were free of charge for clients and, contracts were open-ended. The clients and counselors were asked to keep diaries for the first ten sessions. The clients and counselors exchanged diaries at the end of the eleventh session, and the twelfth session was dedicated to responding to the experience of reading each other's diaries.

Counselor self-disclosure is a disputed issue in therapeutic practice (Knox et al., 1997). The fact that several counselors actually chose to participate in this study does not just reveal courage; it also shows a belief in the clinical importance of authenticity and openness in relationships with clients, values particularly resonant with the humanistic and existential dimensions of the theoretical model the therapists utilized. In none of the cases did client and therapist reading each other's diaries lead to problems that jeopardized the client therapist relationship.

The reason for the exchange of diaries was twofold. First, the study was a launched as a form of participatory research and as such, reading each other's diaries offered each therapist a way of learning about his or her client's perspectives and self-disclosure; and it offered clients a way of reflecting about their lives and relationships with others. Second, the exchange of diaries relieved me from having to conceal the client and counselor perspectives from each other. This was significant, as with the same spirit of self-disclosure and participation, and perhaps a similar sense of trepidation, I also disclosed my analyses of the therapy to the clients and counselors for validation purposes. Thus clients and therapists were first confronted with each other's perspectives before they were confronted with my perspective on their perspectives. Thus they were given the opportunity to differentiate perspectives.

Upon completing the study, clients were asked by email whether they had felt they censored what they wrote about their everyday lives. The response was surprisingly unanimous that they had not been aware of any self-censorship. Some of the diaries seemed to support this as they revealed with extraordinary candor about their troubled lives. With regard to client censorship, colleagues suggested that clients might not express criticism of their counselors in the diaries, but there were examples of this in the data too. Rather than viewing the exchange of diaries as a reason to limit what they wrote in their diaries, clients in this study generally seemed to see this exchange as an opportunity to tell the counselor about their life in ways above and beyond what they said in the therapy sessions. The candor and lack of censorship also seemed to indicate that clients became absorbed in writing. It engaged them and was relevant for them.

After therapists and clients had responded to each other's diaries, the diaries and session recordings were handed over to me. I altered details that could reveal the identities of clients. Therapist names were also altered. A numbering system was assigned to diary entries and paragraphs, for reference purposes. After this, the altered diaries were returned to the clients and therapists. Clients and therapists were asked to sign a statement allowing the researcher to use the data in its anonymous form for research and publication purposes. The pairs of diaries, one for each case, were between 29 and 53 single spaced pages long. 


\section{THE THEORETICAL APPROACH}

The analysis was theory-driven. Presenting the theory used to analyze the diaries in detail goes beyond the scope of this article, so I will offer but a short introduction. The theoretical approach is based on Dreier's "theory of persons in social practice” (Dreier, 2008), which was developed to study psychotherapeutic practice. Dreier's theory is complex and in this study certain key concepts from his study were employed, and certain concepts were adapted to suit the study. Basically, Dreier proposes that we should view clients by focusing on their trajectories. This involves investigating the course of a person's life through contexts and through time. In the present moment, persons are viewed as being on their way to other contexts, and on the way from other contexts; and this is significant for how they are in their present contexts. Psychotherapy sessions are but one context in clients' lives, and according to this approach, the clients' participation in sessions only makes sense when viewed in the light of the client's trajectory. When compared with approaches that try to grasp therapeutic practice merely by investigating the content of sessions, Dreier's approach to psychotherapy research appears radically client-centered.

Dreier grasps a person's relationship to his or her contexts using three central concepts. First he notes that clients and counselors engage themselves in contexts, by pursuing a complexity of concerns. The client in the case presented here, for example, brought certain central concerns with her to the counseling service. She was concerned about understanding her emotional life and about finding "a good man.” Therapists are also concerned participants in therapy sessions. Therapists' concerns reveal their approaches to therapy.

Second, a person's relationship to their context is also related to their structural position. In therapeutic practice, the terms client and therapist refer to structural positions.

Third, a person's relationship to their contexts also has to do with their stances. I use this concept slightly differently from Dreier (see Mackrill, 2008d, pp. 93-96). Some may prefer the term "personal constructs" or "schema" to the term "stance," but the term "stance" is favored as it captures the embodied and contextual nature of personal constructs. Stances are central to how persons participate in contexts. Clients' diaries reveal many stances, for example, stances about how they think they should behave, and stances about how they think they should experience life. They also reveal stances regarding their behavior, their experiences, and their views of the contexts in which they participate. The diaries reveal stances about the past, the present, and the future. As far as this design is concerned, the fact that the term stance is so wide is important. The diaries gathered in this study varied greatly. I therefore needed precise concepts, but ones that were suitably abstract so a diversity of personal experiences could be analyzed in the same way. The concept stance proved adequate in relation to the data produced by the design.

\section{ANALYTICAL PROCEDURES}

This study was exploratory, and as such methods for analysis were developed as it proceeded. As more cases were analyzed, the analytic procedures developed into a set pattern. 
I first read the client and counselor diaries in chronological order, noting the stances represented in the entries, creating one encompassing chronological document that included practically all central client and counselor stances. The next step involved reading this document many times, looking for clients' and therapists’ concerns. David Rennie’s empirical work revealed that clients pursued particular concerns in sessions and that these were sometimes concealed from counselors (Rennie, 1990). Rennie called these pursued concerns tracks. In this project, tracks were presumed to be connected with the clients' concerns outside therapy. Central topics or themes in the diaries tended to reveal client's and therapist's concerns.

The next step in the analytical procedure involved choosing central concerns in the above document that stood out and giving them labels. Once these concerns had been selected, the sections in the encompassing chronological document relating to the chosen concerns were copied into a series of tracking documents. Now, instead of having just one encompassing document containing all central stances in chronological order, I was faced with a series of separate documents containing quotations and stances about specific concerns, with references to where these stances could be found in the original diaries. Importantly, the chronology in the initial document was maintained in these smaller track documents. The track documents presented the diaries in such a way that I could follow the stances related to specific central concerns held by counselors and clients during the course of counseling, through time and across contexts.

The next step in the analytical procedure involved writing up the descriptions and analyses of the clients' and counselor's tracks. The aim of this work was to create a working document (i.e., a case study) that could be presented to the counselor and the client for validation. The analyses were also presented in tutorials with a tutor and two other Ph.D. students who commented on these working documents. Writing up these documents was done one track at a time. Sometimes tracks were connected and therefore written up together. Tracks often ran into each other presenting problems regarding how to write them up. As clients and therapists were to read these working documents, effort was made to make the working documents as reader-friendly as possible. The Jane and Joe case study (Mackrill, 2011) is an example of one of the working documents. When writing a track up, the diary data were subjected to a theory-driven analysis focusing on (a) clients' varied and sometimes contradictory stances; (b) differences in stance between clients and other people in the client's life (including the therapist); (c) shifts in client stances, i.e., where clients adopted new stances; and (d) analyses of the relationship between $\mathrm{a}, \mathrm{b}$, and $\mathrm{c}$ in the light the client's movement between contexts. In essence, the working documents became catalogues describing all central differences and shifts in stances across contexts discovered in the diaries. In the working documents precise references were made to where in the diary stances appeared and were often accompanied by the original quotations. Analyses of how shifts took place across contexts were also presented.

The working document was not solely based on the track documents or the initial encompassing chronological document. Three validation procedures were employed. After the information in the track documents had been written up, I re-read the original diaries, searching for information that could enrich or contradict the description and analysis of tracks in the working document. Sometimes re-reading the diaries shed light on previously unnoticed aspects of the diaries and the analyses in the working document were expanded or altered. Sometimes 
details in the original diaries contradicted analyses in early drafts of working documents, and analyses were revised or abandoned. The initial encompassing documents sometimes turned out to be less encompassing than I had imagined. However, when significant elements were omitted in these documents, these omissions were discovered when the contents of the draft working document was compared with the original diaries.

The second validation procedure involved listening to the recordings of the sessions, which I first heard after reviewing the original diaries. In a process somewhat similar to the one previously described regarding returning to the diaries, I listened to the session recordings to see whether the contents of sessions contradicted or expanded the descriptions and analyses in the working documents. Sometimes analyses had to be abandoned because of new contradictory evidence. Sometimes therapists presented stances in sessions that neither they nor clients mentioned in their diaries. Such evidence was incorporated into the working documents. There were examples where therapists presented stances in sessions before they or their clients presented these stances in their diaries. Such bases for misinterpretations were thus counteracted.

The third step involved sending the working document to clients and counselors for comment. The aim of this was to "let the objects object" (Latour, 2000). Therapists were given the working document and the opportunity of responding to it before it was sent to the clients. Sending a psychotherapy client 29-53, single-spaced pages of a documented analysis of aspects of their life based on psychotherapy sessions and their own diaries per email is something that has given rise to a series of ethical considerations and strategies. First, therapist were forewarned when clients received copies of the working document, as clients were offered the possibility of seeing their therapist (or if their therapist was unavailable, they were offered the opportunity of seeing another therapist who was informed about the project) to discuss any emotional repercussions that might occur in response to reading the working document. Actually, no clients contacted their therapist to deal with emotional repercussions after reading the working paper. Clients were also invited to email me, call me by phone, or meet with me if this was deemed necessary. In the project, I generally corresponded with clients by email. One client called me up to discuss his response to the working document before sending an email response.

The email that was sent to clients with the draft analysis of their case was developed and revised from case to case, even though the contents were similar. Some of the differences in content had to do with what the clients had written in their journals and the fact that the clients had different educational backgrounds. The email accompanying the working paper was written to encourage clients to participate in the research process at this important stage. In the final case analyzed, the client received the following cover email to the draft working paper that she was sent:

It's important that you remember that even though the analysis perhaps looks fine, thought out, and is written in my best English, it is only a construction of your therapy with Joe. It certainly isn't an authoritative understanding of who you are as a person! It is an expression of my speculations and reflections about the changes you have been through. ... I would like your comments. There are places where I interpret or draw conclusions from what you have written, where I may have made mistakes. I translate what you have written, which is another source of error. And I have chopped your journal into pieces and put it back together to serve my own purposes and your perspective may have been lost in the process. ... It is 
important to me that your viewpoints have not been distorted, so write if you disagree or if you feel your point of view has been misrepresented. If you disagree with what I have written, write a suggestion as to how I should understand what you have written. You are of course welcome to disagree without having an alternative suggestion. Please write other thoughts you find interesting and would like to share with me down. The draft I am sending is not a final product. If you do not comment, I will presume you do not disagree with what I have written.

The email that followed the draft working paper also included suggestions as to how clients might write comments. There was a little introduction regarding how to insert comments in a Microsoft Word document. Otherwise clients were told that if they wrote comments, they must remember to note which page they were commenting on. Clients were also told they could receive a hard copy and a stamped, addressed, return envelope by regular mail if they preferred to write their comments onto a hard copy.

The fact that clients were expected to change in time also meant that asking them to validate their own points of view was problematic. In order to counter this, when clients were sent the working case study document, they were reminded in the cover email that

It is important to remember that this is a process. You may see things in a different way now. I am trying to grasp the process, so only correct when you think I have misunderstood or misrepresented how you felt back then.

All the clients offered corrections of one kind or the other. Therapists also corrected the working documents where they felt misinterpreted. The therapist and client corrections were used to further develop the working documents. When I was not sure what the client meant, email correspondence took place until points were cleared up. Only one client was initially angry and felt he was misrepresented several places in the initial draft. This useful criticism led to a fruitful correspondence that ended up with the client being satisfied with the final draft. When there were a significant number of points to clear up, the client and counselor were sent a revised version of the working document that strove to incorporate their comments, to check whether the new version gave an adequate representation of their stances. When there were few corrections, clients and counselors were not sent revised versions of the working document. No face-to-face meetings were held with clients.

Generally speaking, both clients and counselors were excited about receiving the analyses, and they were generally interested in responding to the analyses. Some were moved by the fact that I had spent so much time looking at their life or work. Some clients also expressed sadness when they read about themselves and their struggles. Four of the eight case for whom data was collected were not analyzed. Two were not analyzed because the clients had written relatively few details about their every day lives. The other two were not analyzed for ethical reasons, including one that would have involved my sending a long document highlighting the clients' contradictory stances that I deemed too confrontational for this particular client at this particular time. 
As clients were expected to change during the course of therapy, they were reminded that they should only correct the working paper when I had misunderstood or misrepresented how they felt at the time they were writing. Therapists were given a similar reminder.

The way the cases were written was similarly tailored to suit the clients' and therapists' educational backgrounds. The Jane and Joe case (Mackrill, 2011) included a fairly rich theoretical introduction to the method. The other cases did not contain such a dense introduction.

Thus the descriptions and analyses in the working documents were cross-checked or validated in three ways: first in relation to the original diaries; then, in relation to the session recordings; and finally, by submitting them to the therapist and client for feedback. While the first two procedures were ways of validating the working document as a whole, the final procedure only validated the representations of client and therapist stances. The analyses themselves are obviously solely the responsibility of the researcher in this design.

\section{TRIANGULATION ISSUES}

In qualitative research, comparing information from different sources is a standard way of validating knowledge. This method is called triangulation (McLeod, 2001 p.187). The idea behind triangulation is the notion that achieving a consensual view makes for better knowledge. Triangulation as a method takes various forms in this design and involves three central issues. First, if an informant, typically a client, presented various stances in relation to the same issue in one diary entry, I did not necessarily conclude that the information given was invalid due to the lack of consensus. I might conclude that the client had different stances in relation to the same issue. Many clients come to therapy precisely because they are in conflict with themselves. This does not render their stances invalid.

Secondly and similarly, if an informant presented differing stances at different points in time, I did not necessarily conclude that the information given was invalid. I considered whether this once again was an example of the clients expressing different stances or whether the stances being expressed were new to the client's life practice, in which case the differences in stance were considered a possible shift in stance. Psychotherapeutic practice is about change, and employing a scientific method that invalidates findings that suggest change would be disastrous.

Thirdly, triangulation is often understood as corroborating data by comparing the viewpoints of informants. In this study, when clients and therapists had different stances about the same issue, their stances were not considered invalid. The existence of different stances about the same issue on the part of clients and therapists was considered central to psychotherapeutic practice. I was actually surprised to discover that there was considerable consensus in postsession diary entries about what clients and therapists considered significant in sessions. The existence of these three issues, however, did not make the notion of triangulation redundant in the project, although it complicated matters.

In effect, the final working documents were socially constructed representations of therapeutic practice, which focused on (a) a client's varied and sometimes contradictory stances; (b) differences in stance between a client and others (including the therapist); (c) shifts in client 
stances; and (d) analyses of these three aspects and their relationship to the contexts in the client's life. Despite this complexity, triangulation was still central to the design. The constructions that were created were triangulated by comparing the construct as a whole with the data in the diaries; with the data in the session recording; and with the client's and therapist's recollections of what had occurred. The aim of these procedures was to seek out evidence that disproved or amended aspects of the construct as a whole. The final working documents were thus systematically created products that were guided by Dreier's theory and that took into account a variety of points of view, that is, these documents were socially constructed case studies.

\section{DIARY DATA AND CONTEXTS: A DISCUSSION}

The case studies were designed to generate a systematic and rigorous construction of psychotherapeutic practice that incorporated aspects of clients' lives outside sessions and their significance for client change. The study revealed how clients employed strategies for change that they had accessed before coming to therapy sessions (see Mackrill, 2008c). The study revealed how clients encountered therapeutic thinking from a range of sources other than the therapy sessions while in therapy and how this was significant for their therapy (see Mackrill, 2009b). The study showed how therapeutic sessions were one activity among several in which clients participated in their attempts to get better. The study showed that clients combined activities across contexts.

The diaries also offered theoretical insights into the psychotherapy as a cross-contextual practice. Where Dreier (2008) emphasizes clients' physical trajectories through space and time, this study also revealed the centrality of a person's mental movements across contexts and times. When clients were in one context physically, let us say the therapy room, they often remembered or imagined other contexts mentally. Similarly when in other contexts, clients sometimes remembered what occurred in therapy sessions or in other significant contexts. When in one context, clients remembered past contexts, imagined future contexts, or imagined what was going on in other contemporary contexts.

This remembering and imagining was affected by the particular context in which it occurred. Clients, like all people, constantly move through time and space on two different levels. There is a physical trajectory that has to do with being in specific contexts at specific times, and while on this trajectory, clients may imagine other times and contexts. During the course of the study it became apparent that the dual nature of clients' contextuality was central to understanding therapeutic practice. Client problems were often about making sense of past contexts; or making sense of what occurred in contemporary contexts in which they were not immediately present; or envisioning how hoped for future contexts might come into being. Making comparisons and connections across contexts and times was central to clients' therapeutic practice. Finding themselves unable to make cross-contextual connections was often central to what brought clients into counseling in the first place. Sometimes clients' mental movements across contexts that occurred in sessions, or other contexts were followed by corresponding physical movements, as clients' traveled to challenge and develop their mental versions of contexts. This cross-contextual construction of clients' therapeutic practice is one of the study's most central findings. 
The diary approach offered a particular kind of access to clients' contexts. The clients were influenced by the guidelines, as they reviewed what they had experienced that was new or different since the previous session. However, the diaries clearly had other functions for the clients. Clients often used their diaries as if it were a place, a geographic location in time, where they could try and make sense of aspects of their lives without their therapists, friends, or others being present. This focus was clearly not to fulfill counselor or researcher expectations, but to fulfill their own curiosity about their lives. Diaries are a reflective medium that access subjects' sense-making as a process occurring across time and contexts. As such clients used their diaries in accordance with its possibilities as a medium. As mentioned, historically speaking, diary writing has been employed for personal and religious development (Alaszewski, 2006) Symes, 1999). The diaries reflected both an "I" and a "me" to use Mead's terms, and sometimes they reflected many "I” positions (Raggatt, 2000). The diaries accessed the clients' contexts as part of their sense-making endeavors.

Clients also used their diaries as a means of communication to tell the counselor, the researcher, and future readers of the researcher's work about their lives beyond what they could say in sessions. But equally important, clients used diaries as a means of communicating with themselves. Clients frequently condemned and condoned themselves for their behavior in their diaries. Clients also used their diaries to reveal new aspects of themselves to themselves. Interestingly, one client revealed new aspects of her suffering to herself in her diary before revealing this suffering to her counselor in a session. The counselor experienced a breakthrough when the client expressed this suffering in a new way in the following session. The counselor was correct in this assessment to a certain extent, as this was the first instance where the client revealed this suffering to someone else. But equally important to the client was the experience of facing the suffering at home on her own, prior to the therapy session. This example shows how research designs that solely focus on the content of sessions can skew one's understanding of psychotherapeutic practice. Thus the diaries accessed contexts as part of clients' communicative endeavors.

The two above points highlight a third important feature of diary data. Although I had asked clients to review the time that had passed since the last session, clients sometimes wrote about experiences in real time, relaying what they were experiencing while they wrote their diaries. Thus the diary method granted both retrospective and real-time access to clients' contexts. Furthermore, clients sometimes also used their diaries to reflect about their possible futures. Thus the diary approach offered a view of past, present, and imagined future contexts.

The contents of the diaries were thus subject to selectivity beyond the selectivity proposed in the guidelines. As the diary data were rich in detail, I chose to analyze the diaries as presented by the clients and counselors without a follow-up interview to gather more information about the clients' lives elsewhere (Zimmerman \& Wieder, 1975). Client selectivity is a central challenge in a diary study, as the researcher relinquishes considerable control over the research process. Two client diaries were not analyzed due to a lack of data concerning their everyday life contexts, in spite of the fact that this was clearly described as the aim of the project in the guidelines. Gathering more diaries than necessary is therefore important when considering a diary approach. Often clients did not follow the letter and number system suggested in the guidelines. In entries that were meant to be about significant aspects of sessions, clients often 
chose to write about their lives outside sessions. Clients generally seemed more interested in writing about their lives outside sessions than about the contents of sessions.

The selectivity of diary data is both the method's greatest strength and weakness. Diary methods offer a unique view of clients' subjectivity. However, details about how clients' contexts were structured were limited. Interviewing clients about the contexts of their everyday lives would offer an access to clients' everyday lives that was less sporadic. Interview methods offer more detailed accounts both of the contexts of the clients' lives and about how the client participated in these contexts. Interviews offer the researcher the opportunity of greater systematization when gathering data. An interviewer would be able to keep the client on track and probe interesting aspects of what the client was saying. Other researchers might also consider a diary/interview option. Asking clients to keep diaries and then subsequently interviewing them about specific contexts and their participation in them might counter the limitations client selectivity puts on diary data. The clients in this study were told they might be interviewed, and this did not seem to restrict what they wrote in their diaries.

The clients' selectivity also revealed another problem with the diary method. It did not offer alternative views of the clients' contexts. In an interview study, interviewing significant others about changes in the clients' everyday life is a possibility. This might offer a different view of clients' contexts. Such an approach has been employed by Dreier (2008), who interviewed family members.

This study also suggested that the more structured a diary design is, the less access it grants to clients' subjective processes. Thus a highly structured diary approach is more suited to quantitative data. Structured diary approaches, however, sometimes face problems related to diarist motivation (Bolger et al., 2003 p. 593). They risk boring participants and thereby gathering poor data. The advantage of the semi-structured approach presented here was that most diarists found the process stimulating. They experienced it as personally relevant.

\section{THE DIARY METHOD AND LATER MOMENTS OF QUALITATIVE RESEARCH}

This study employed Dreier's (2008) theoretical framework. Dreier (2008) develops the concept of client change. Dreier conceives change as something that is pursued across contexts as clients link experiences. Dreier conceptualizes four ways in which personal change is related to changes in the contexts of the clients' lives.

(1) Sometimes contexts basically remain the same, but a person changes their personal stance to the contexts. For example, a person may become less affected by hurtful things someone else says about them, as they come to the conclusion that the other person is an unreliable judge of character.

(2) Sometimes change involves taking a new behavioral position in a context. This type of change involves adjusting the division and coordination of tasks within a given context. For example, a family member may begin to take more or less responsibility for doing the washing up, cleaning, and cooking. 
(3) Sometimes contexts change and people do or do not change with them. For example, as children grow up, parents may or may not change their parenting to suit the age of the children.

(4) Change may also involve changing the scope of possibilities within a context as a whole. In a family context, this might involve changing employment situations, finding a different family home, or buying or selling a car due to a new financial situation.

My diary study revealed a fifth way in which personal change may be related to clients' contexts. Clients also change by distancing themselves from certain contexts. A client may, for example, change by seeing less of their problematic alcoholic parents. The diary study also revealed that the process of change involves clients distancing themselves from contexts. For example, when adult children of alcoholics leave home, the experience of living in a new home offers perspectives both on what living with their alcoholic parent(s) was like and what living without their alcoholic parent(s) is like (Mackrill, 2008b). By participating in new contexts, clients gain new perspectives on the context from which they are distant, on the one hand, and their present context, on the other. Therapy sessions are one example of a distant context that clients may use to change, but clients also use other distant contexts to gain new perspectives and change.

While the therapy diary journal has these roots, it is also inspired by phenomenology, post-positivism, hermeneutics, social constructionism, and action research. Thus the project follows Kvale's (2001, 9-29) proposal and charts an epistemologically pluralistic course. The project is inspired by phenomenology in the sense that the diarists are required by the guidelines (see Appendices 1 and 2) to do two things. First, the diary writers are required to suspend their desire to explain and are rather to focus on describing the phenomena they experience. They are later asked to seek possible explanations for these phenomena. Second, the clients are asked to report all new or different experiences regardless of how significant they consider them to be. This follows the phenomenological concept of "horizontalisation" (Spinelli, 2005, p.21).

The diary project is post-positivist in that validation procedures are employed to attempt to falsify the construction created. The project is inspired by hermeneutics in the sense that the construction of therapeutic practice generated involves a process of weaving backwards and between the various texts of which the project is comprised. I am here also referring to the session recordings as a form of text and the participants as bearers of text. The validation procedures are not just used to falsify the text. The text is developed as it is compared with the original diaries, the session recordings, and the participants' recollections. Moving back and forth between sources of data in the creation of a text lies at the heart of hermeneutic methodology.

The project is also inspired by social constructionist thought in the sense that it is built on the premise that all scientific results are constructed through a series of methodological assemblages (Law, 2004) and that scientific results can best be assessed by making these assemblages explicit. The research thus offers a positioned view of psychotherapeutic practice. 
The study also adheres to Denzin and Lincoln's (1994b) fifth moment of qualitative research in the sense that the research is action-oriented and political. It is action-oriented in that the client and the therapist are viewed as co-researchers, and in that participating in the project is thought of as a way that may contribute to changes in their professional and life practices and thus as a way of empowering them (Meth, 2003, p.201; Meth, 2004, p.154).

The research is political in the sense that it draws attention to the client as a competent agent rooted in social practice. Much psychotherapy research depicts the client as ultimately suffering from disorders that are cured by psychotherapeutic interventions. The therapy journal project is thus "anti-psychiatric" in the sense that it instead depicts the client as facing troubles relating to how their everyday lives are structured, and cure is viewed as relating to client action. The use of client validation of the work is another key aspect of this, as the client is offered an active role in securing the trustworthiness of the findings. Thus the research includes the quality of "being with and for the other, not looking at" the other (de Laine, 2000, p. 16). This differs from, for example, consensual approaches where trustworthiness is secured by consensus among researchers (e.g., Hill, Thompson \& Williams, 1997). The client is thus not just depicted as an agent by the researcher; the client is a central agent in the generation of the research. The research reframes how the client is typically incorporated and depicted in an attempt to create psychotherapy research that is for clients, as well as for therapists. The project is thus also rooted in what McLeod (2001, pp.17-19) introduces as a seventh moment in qualitative research, where research plays a part in "reconfiguring therapy in response to social and cultural change" and in re-inventing psychotherapeutic practice as a socio-cultural rather than merely a psychological practice.” McLeod's notion here seems to correspond to what Denzin and Lincoln (2005b, p.1117) also call a seventh moment, which relates social research to social purpose. In addition, Denzin and Lincoln (2005a, p.20) refer to an eighth moment where scholars confront the methodological backlash associated with the evidence-based social movement. The approach presented here also adheres to this moment as it is in effect one long engagement with the position that emphasizes ascribing psychotherapeutic cure to professional interventions.

\section{INTRODUCTION TO THE JANE AND JOE CASE}

The Jane and Joe case that is presented in this journal issue (Mackrill, 2011) was the first case in the diary project to be studied. The case was written for the client and the therapist and their amendments to the case have been incorporated into the case's final text. No further adjustments have been made.

The Jane and Joe case is "raw data" for another case in this journal (Bohart et al., 2011). The Jane and Joe case study is written in a style presumed to be accessible to the client and therapist. Any case study is an angled summary or construction of what occurs in a given course of therapy. The richness of the phenomenon is always lost in the particular view presented in a given case. In closing this introduction to the Jane and Joe case, a more traditional outline of the case is presented below. 


\section{Jane's Presenting Problems}

According to Joe the therapist and his referral notes, Jane's presenting problems are (1) memories that bother her on a daily basis, and Jane's sense of vulnerability in relation to these; (2) Jane's experience of being very sensitive; (3) Jane's low self-esteem; and (4) Jane's insecurity with regard to close relationships with men.

\section{Joe's Theoretical Orientation}

Joe's theoretical orientation is humanistic and existential. Joe is a trained Gestalt therapist, but is also inspired by the many versions of existential psychotherapy. Joe negotiates the goals for therapy with Jane, basing the therapy primarily on Jane's goals. Joe's work is phenomenologically inspired. Joe often asks Jane to describe her experiences in detail without interpreting. Joe uses his experiences of his contact with the client as a guideline for the therapeutic process. Joe talks about his ongoing relationship with Jane and encourages Jane to do the same. Joe views his relationship with the client as an example whereby the client can learn about relationships. Joe sometimes makes interpretations, for example, he interprets Jane's crying as grief. Joe is supportive in relation to concrete problems Jane faces, such as her relationships with men. Joe sometimes offers Jane alternative ideas about what she might do, or how she might understand something, when he feels this might help.

\section{Joe's View of the Main Themes in the 11 Therapy Sessions Included in the Diary-Writing Process}

According to Joe's diary the main themes of the first session were establishing contact, working on goals and memories from the past.

The topic of the second session was Jane's relationship to her father and Jane's relationship to men in general, as well as Jane’s relationships with friends.

The focus in the third session was Jane's experience of a date she was on prior to the session and Jane's wishes with regard to relationships. Another topic was Jane's relationship with her brother.

The main topics in the fourth session were further experiences with the date and the significance of Jane's upbringing for her relationships with men. Another focus was Jane's experience of not being as tough as she used to be.

In the fifth session the relationship with the date was again a topic, as a well as Jane's death anxiety in relation to her mother and brother.

In the sixth session a major topic was a headache that Jane had had for years, as well as memories from the past and grief.

In the seventh session the main topics were once again Jane's sense of sadness and grief, as well as Jane’s desire to have a family and Jane's relationship with men. 
The following two sessions (eighth and ninth) focused on traumatic experiences from Jane's childhood and the significance of sharing experiences. Jane's relationship with her mother was also a topic in these sessions.

In the tenth session a main theme was the dilemma between sharing experiences versus keeping them to oneself. Jane's relationship with her mother was once again a theme, as well as a difficult experience from Jane's youth.

In the eleventh session the topic was primarily a concrete experience of Jane's mother being drunk prior to this session and Jane's concerns in relation to this.

In the twelfth session, the focus was on Jane's role in her family and once again on Jane's relationships to men.

\section{Case Outcome}

After the 12 sessions Jane was less troubled by memories from the past. Jane gained a new understanding of how her past influenced her present and this seemed to lead to less self blame. Jane gained a new perspective on her relationships with men, and started experimenting with a different way of being in a relationship with a man. Jane began to focus more on how she could achieve what she wanted in her relationships with others. Jane's self-esteem appeared generally to have improved. The therapy continued after the 12 sessions, but the diary-writing project and my contact with Jane and Joe ended at this point.

\section{REFERENCES}

Alaszewski, A. (2006). Using diaries for social research. London: Sage.

Bohart, A.C., Tallman, K.L., Byock, G. \& Mackrill, T. (2011). The "Research Jury” Method: The application of the jury trial model to evaluating the validity of descriptive and causal statements about psychotherapy process and outcome. Pragmatic Case Studies in Psychotherapy, 7(1), Article 9, 101-144, Available: http://hdl.rutgers.edu/1782.1/pcsp_journal

Bolger, N., Davis, A., \& Rafaeli, E. (2003). Diary methods: Capturing life as it is lived. Annual Review of Psychology, 54, 579-616.

Coxon, A.P.M. (1996) Between the sheets: Sexual diaries and gay men's sex in an era of AIDS. London: Cassell.

de Laine, M. (2000). Fieldwork, participation and practice: Ethics and dilemmas in qualitative research. London: Sage.

Denzin, N.K., Lincoln, Y.S. (1994a). Introduction: Entering the field of qualitative research, in N. K. Denzin \& Y. S. Lincoln (eds.) Handbook of qualitative research. $2^{\text {nd }}$ ed., 1-17. Thousand Oaks, CA: Sage.

Denzin, N.K., \& Lincoln, Y.S. (1994b). The fifth moment. In N. K. Denzin \& Y. S. Lincoln (eds.) Handbook of qualitative research. $2^{\text {nd }}$ ed., 575-586. Thousand Oaks, CA: Sage.

Denzin, N. K. \& Lincoln, Y. S. (2005a). Introduction. The discipline and practice of qualitative research. In N. K. Denzin \& Y. S. Lincoln (eds.) Handbook of qualitative research $3^{\text {rd }}$ ed., 1-32. Thousand Oaks, CA: Sage 
Denzin, N. K. \& Lincoln, Y. S. (2005b). Epilogue: The eighth and ninth moments - qualitative research in/and the fractured future. In N. K. Denzin \& Y. S. Lincoln (Eds.), Handbook of qualitative research, 3rd edition, 1115-1126 Thousand Oaks, CA: Sage.

Dreier, O. (1998.) Client perspectives and uses of psychotherapy. The European Journal of Psychotherapy, Counselling and Health, 1, 295-310.

Dreier, O. (2008) Psychotherapy and everyday life. London: Cambridge University Press.

Evans, I.M., \& Robinson, C. H. (1978). Behavior therapy observed: The diary of a client. Cognitive Therapy and Research, 2, 335-355.

Goss, S., \& Mearns, D. (1997). A call for a pluralistic epistemological understanding in the assessment and evaluation of counselling, British Journal of Guidance and Counselling, 25, 327-44.

Hill, C. E., Thompson, B. J., \& Williams, E. (1997). A guide to conducting qualitative research. The Counseling Psychologist, 25, 517-572.

Hill, C. E. (2004). Helping skills: Facilitating exploration, insight, and action (2 ${ }^{\text {nd }}$ ed.). Washington, DC: American Psychological Association.

Knox, S., Hess, S. A., Petersen, D.A., \& Hill, C.E. (1997). A qualitative analysis of client perceptions of the effects of helpful counselor self-disclosure in long-term therapy. Journal of Counselling Psychology, 44, 274-283.

Kvale, S. (2001). The psychoanalystic interview as qualitative research. In J. Frommer \& D. Rennie (eds.), Qualitative psychotherapy research: Methods and methodology, 9-29, Lengerich, Germany: Pabst Science.

Latour, B. (2000). When things strike back: A possible contribution of "science studies" to the social sciences. British Journal of Sociology, 50, 107-123.

Law, J. (2004) After method: Mess in social science research. New York: Routledge.

Levine, M., \& Calvanio, R. (2007) The recording of personal information as an intervention and as an electronic health report, In L. L’Abate (ed.), Low-cost approaches to promote physical and mental health. Theory Research, and Practice, 227-250, New York: Springer.

Mackrill, T. (2007). Using a cross-contextual qualitative diary design to explore client experiences of psychotherapy. Counselling \& Psychotherapy Research, 7, 233-239.

Mackrill, T. (2008a). Solicited diary studies of psychotherapeutic practice: Pros and cons. European Journal of Psychotherapy \& Counselling,10, 5-18.

Mackrill, T (2008b) Pre-treatment change in psychotherapy with adult children of problem drinkers: The significance of leaving home. Counselling \& Psychotherapy Research, 8, 160-165.

Mackrill, T. (2008c). Exploring psychotherapy clients' independent strategies for change while in therapy. British Journal of Guidance and Counselling, 36, 441-453.

Mackrill, T. (2008d) The Therapy Journal Project: A cross-contextual qualitative diary study of psychotherapy with adult children of alcoholics. PhD Dissertation. Copenhagen: Institute for Psychology, Copenhagen University.

Mackrill, T. (2009a). Constructing client agency in psychotherapy research. Journal of Humanistic Psychology, 49, 193-206.

Mackrill, T. (2009b). A cross-contextual construction of clients' therapeutic practice. Journal of Constructivist Psychology, 22, 283-305. 
Mackrill, T. (2011). The case of “Jane and Joe”: A diary-based, cross-contextual case study. Pragmatic Case Studies in Psychotherapy, 7(1), Article 10, 187-229. Available: http://hdl.rutgers.edu/1782.1/pcsp_journal

McLeod, J. (2001). Qualitative research in counselling and psychotherapy. London: Sage.

Meth, P. (2003) Entries and omissions: Using solicited diaries in geographical research. Area, 35, 195-205

Meth, P. (2004) Using diaries to understand women's responses to crime and violence. Environment and Urbanization, 16, 153-164.

Raggatt, P.T., (2000) Mapping the dialogical self: Towards a rationale and method of Assessment. European Journal of Personality, 14, 65-90.

Rennie, D.L. (1990) Towards a representation of the client's experience of the psychotherapeutic hour. In G. Lietaer, J. Rombauts, \& R. Van Balen (Eds.), Client-centered and experiential psychotherapy in the nineties, 155-172. Leuven, Belgium: Leuven University Press.

Resick, P.A., Monson, C.M., \& Rizvi, S.L. (2008). Post-traumatic stress disorder. In D.H. Barlow (Ed.), Clinical handbook of psychological disorders: A step-by-step treatment manual (4th ed.), 65-122. New York: Guilford Press.

Rogers C. R. (1951) Therapy: Implications and theory. Boston: The Riverside Press.

Seale, C. (1999). Quality in qualitative research. Qualitative Inquiry, 5, 465-478.

Sheridan, D. (1993). Writing to the archive: Mass observations as autobiography. Sociology, 27, 27-40.

Spinelli, E. (2005). The interpreted world: An introduction to phenomenological psychology, $2^{\text {nd }}$ ed. Thousand Oaks, CA: Sage.

Symes, C. (1999). Chronicles of labour: A discourse analysis of diaries. Time and Society, 8, 357-380.

Tolman, C., \& Maiers, W. (1991). Critical psychology: Towards an historical science of the subject. Cambridge: Cambridge University Press.

Thiele, C., Laireiter, A-R., Baumann, U. (2002) Diaries in clinical psychology and psychotherapy: A selective Review. Clinical Psychology and Psychotherapy, 9, 1-37.

Wosket, V. (1999). The therapeutic use of self: Counselling practice, research and supervision. London: Routledge.

Yalom, I., \& Elkin, G. (1974). Every day gets a little closer. A twice-told therapy. New York: Basic Books.

Yin, R. K. (2003). Case study research: Design and methods, 3rd ed. Thousand Oaks, CA: Sage. Zimmerman, D., \& Wieder, D. (1975). The diary-interview method. Urban Life, 5, 479-497. 


\section{APPENDIX 1. The Therapy Journal Project - Client Guidelines}

Participation in this project is voluntary. If you chose to participate, try to follow through with the project. You can, of course, stop if you want. If you chose to do this, tell your therapist. This will not affect your continued therapy at the counselling service.

If you chose to participate, you chose to become a researcher, researching your own life and how you use therapy. This is what this project is about - researching how clients such as yourself change and how you use therapists! We would like to know more about, how what happens in therapy sessions is connected with your life outside therapy, so we can become better therapists and develop our way of doing therapy at the counselling service.

Participation in the project can support your therapy. Being in therapy is about researching your own life. It is about becoming wiser, as to why one's life is as it is and investigating possibilities for change. Participation in this project may help you with this.

In brief, the project involves you and your therapist writing logs after each session about what you consider significant. You must do this for a course of 10 sessions. You must also write a log prior to each session about new or different experiences in your life. Altogether, you must write 20 times, twice between every session. After the 10 sessions you exchange journals with your therapist for a discussion. The sessions will be recorded.

It is important that you only participate if you really want to, and that you like writing - the more details you can write, the more we can learn. There may be certain things that you chose to keep to yourself. This is, of course, fine. To participate, you have to want to immerse yourself in the task and write! If you don't want to participate - say no thank you.

The Therapy Journal Project is a co-operation between the counselling service and the Centre for Alcohol and Drug Research (CRF), AArhus University. The researcher from CRF, Thomas

Mackrill, was formally a therapist at the counselling service.

\section{The Method}

You must write a journal in connection with 10 therapy sessions. You must write twice between sessions - after each session and prior to the following session. When you write - follow these instructions.

1) After each session (preferably within 48 hours) - answer the following questions and write as detailed as possible.

\section{a) What was significant for you in the sessions?}

Try and describe everything that was significant as precisely as a possible. You are welcome to write a lot. Note what was particularly significant for you. Give each significant thing a number (1,2,3, etc). 
For example - perhaps you talked about something important (describe what it was). There may be things the therapist said or avoided saying that were important (describe them). Perhaps the way the therapist was together with you was important (describe how the therapist was). Perhaps other things were important to you. E.g. that the therapist said hello in the usual way; or that the therapist looked tired/happy. Perhaps the chairs in the therapy room were positioned differently or the therapist didn't notice your new hairstyle? Write what you thought was significant, however great or small you consider the detail. We want to learn. Remember, no detail is too trivial to write about.

\section{b) Write you thoughts down about why these things were significant for you.}

Go through the significant things you have noted in (a), one after the other, and write your reflections down about why you consider them significant. Give these numbers too (1a, 2a, 3a etc.) So we can see what you are reflecting on. If you don't have any thoughts as to why something was significant, just write 'I don’t know'.

Remember to write the date each time you write.

\section{2) Before the next session (preferably within 48 hours)}

\section{a) Write a log about the time that has passed since the last session focusing on....}

New things you have down in your life. Things you have done in different ways. Things you have experienced in different ways, since the last session.

Once again try to describe everything as precisely as you can, with as many details as possible. You are welcome to write a lot. Sit yourself down when you have time there is peace and quiet and, and mentally go through the time that has passed since the last session - day by day (hour by hour) and think about where you were and what you did. Write all the new/different experiences down, however great or small they seem to you. Give each experience a number (1,2,3, etc.) For example, perhaps you were in town and bought new clothes, or you tasted a new kind of cheese, or you saw a different TV programme. Maybe you said something to someone that you hadn't said before. Maybe you experienced other people in new ways or you experienced yourself in a different way. Perhaps you went somewhere you hadn't been before or you went somewhere in a different way (by bus, with a friend, alone). But don't let these examples limit what you write. Please write in detail, e.g. "I visited my old friend Ida, who I knew from school, at her apartment. She seemed different to me, when she talked about her boyfriend. She seemed unsure of herself. Previously she always seemed to be sure of herself" etc. The point of the journal is that we can get a picture of the new or different things you experience in your everyday life, as you move from place to place in your everyday life. 
If you donlt feel so good one day and find writing your log difficult, start by writing how you feel. You may be able to answer the questions afterwards. If writing is still too difficult, give yourself a break. Be good to yourself. Try again the following day. Write down why you couldn't write ,e.g." today I was too sad to write".

\section{b) Try to explain why you experienced these different or new things.}

Go through the new/different experiences one by one and investigate your own thoughts as to why you experienced them. Give these reflections numbers (1a,2a,3a, etc.), so we can see which particular experience your thoughts are referring to. If you don't have any thoughts as to why you experienced something new/different, write ”I don’t know”. Perhaps you just did something because you felt like it. Or perhaps if you think about it, you had several reasons for what you did. E.g. "I bought new clothes because my friend, Ida, had said that blue suited me, so I just had to go out and find something in blue; and at the same time I just needed some new clothes". Or "I called up a friend and told him how I felt, as I was lonely and fed up, and felt it was time to do something about it, so I didn't end up like my dad.” Or “ I don't really know why I experienced Ida as unsure of herself. Perhaps, I noticed that she is not as different from me as I thought.” Once again remember both that you are more than welcome to write a lot with a lot of details and that nothing is to trivial to write.

\section{c) What part do you think the sessions played in these new/different experiences?}

Go through the new/different experiences once again one by one and see what thoughts you have about how the sessions played a part in them. Give these reflections numbers ( $1 \mathrm{~b} 2 \mathrm{~b}$, $3 \mathrm{~b}$ etc.) so we can see which new/different experiences you are referring to. If you don't think the sessions played a part the new/different experience, this is fine. Just write 'I can't see a connection with the sessions.' But you may have thoughts as to how the sessions played a part in the new different/experiences. Write these thoughts down.

\section{d) When have you thought about the therapy sessions since the last session? In what situations have you thought about the sessions and what have you thought? Write in as much detail and as precisely as possible.}

\section{What else will happen?}

Your therapist will also write a journal. After each session s/he will answer the following questions.

What was significant for you in the session to day?

How do you think these significant things played a part in the client's life outside therapy?

At the eleventh session you exchange journals and the following $1 \frac{1}{2} 2$ hour session, you have the opportunity of discussing the experience with each other.

Experience has shown that some clien's become nervous at the thought of reading what the therapist has written. If you feel nervous about this, try waiting to read what s/he writes until just before the next session, so you don't have to hold on to potential questions for too long. 
Your journals are then handed over to the researcher, Thomas in WORD format together with the recordings of the sessions.

Thomas will give you both pseudonyms and make sure you are not recognised. Thomas will continue to change the texts until you feel sure your identity is concealed. The recordings will be used to see what you are referring to in your journal, when this is necessary.

Thomas will then ask for your written permission to publish the material and use the material in its anonymised form in reports and articles. He may also write a book.

Thomas may later want to interview you. The content of such an interview would be confidential.

If you have any questions you are welcome to mail or call Thomas, but you can also talk to your therapist who knows him.

Thomas Mackrill Phone number Email address.

\section{Method checklist - Please write in WORD format. Remember to write the date in every log.}

1) After each session (preferably within 48 hours) Answer the following questions and write in as much detail as possible.

\section{a) What did you find significant in the session?}

Describe everything you found significant in as precisely as possible. Give each significant thing a number 1,2,3,etc. Write about whatever you found significant, however great or small you consider the incident to be. We want to learn. You are welcome to write a lot. Note if you find something particularly significant. Remember - nothing is too trivial for the journal.

b) Write you thoughts down about why these things were significant for you. Go through the significant things you have noted in (a), one by one and write your reflections down about why you consider them significant. Give these numbers too (1a, 2a, 3a etc.) so we can see what you are reflecting on. If you don’t have any thoughts as to why something was significant, just write ‘I don’t know’.

2) Before the next session (preferably within 48 hours)

a) Write a log about the time that has passed since the last session focusing on....

New things you have down in your life; Things you have done in different ways. Things you have experienced in different ways, since the last session. 
Try to describe everything as precisely as you can, with as many details as possible. You are welcome to write a lot. Sit yourself down, when you have time and there is peace and quiet and mentally go through the time that has passed since the last session - day by day (hour by hour) and think about where you were and what you did. Write all the new/different experiences down, however great or small they seem to you. Give each experience a number $(1,2,3$, etc. Remember - nothing is too trivial for the journal. We may find something important you consider trivial. The point of the journal is that we can get a sense of the new/different things you experience in your everyday life as you move about from place to place. Please write a lot.

\section{b) Try to explain why you experienced these different or new things.}

Go through the new/different experiences one by one and investigate your own thoughts as to why you experienced them. Give these reflections numbers (1a,2a,3a, etc.), so we can see which particular experience your thoughts are referring to. Remember - nothing is too trivial for the journal. We may find something important you consider trivial. Once again you are welcome to write a lot and in detail.

Remember - nothing is too trivial for the journal. We may find something important you consider trivial. If you don't have any thoughts as to why you experienced something new/different, write "I don't know".

\section{c) What part do you think the sessions played in these new/different experiences?}

Go through the new/different experiences once again one by one and see what thoughts you have about how the sessions played a part in them. Give these reflections numbers ( $1 \mathrm{~b} 2 \mathrm{~b}$, 3b etc.) so we can see which new/different experiences you are referring to. Remember - nothing is too trivial for the journal. If you don't think the sessions played a part in the new/different experience, this is fine. Just write 'I can't see a connection with the sessions.'

\section{d) When have thought about the therapy sessions since the last session? In what situations have you thought about the sessions and what have you thought? Write in as much detail and as precisely as possible.}




\section{APPENDIX 2.}

\section{Therapist Guidelines}

\section{The Therapy Journal Project}

The aim of this project is to investigate the connection between the contents of psychotherapy sessions and changes in clients' lives. If you participate in the project, you must be interested in investigating this, as you will become a co-researcher in your own practise. Another aim of the project is to contribute to the development of the psychological service offered. I hope the project will make us more knowledgeable as to how clients use psychotherapy.

In brief, the project involves both you and your client after each session writing journals about what you think is significant during a course of ten sessions. The client must also write a log each week about new and different experiences in his/her life. Altogether the client writes twenty logs - twice between each session and you write ten logs. At the eleventh session you exchange journals and the following twelfth $1 \frac{1}{2}$ hour session, you have the opportunity of discussing the experience with each other. You also record the sessions $(1-10+12)$.

It is important that you participate voluntarily and that you like writing. The more you can write, the more we can learn. So you just have to want to immerse your self in the project! The project is for the brave, as it involves giving both the client and I (and potential readers) access to your thoughts about your therapeutic practise. There are probably things you chose to keep to yourself. This is of course ok. The project is inspired by Yalom and Elkin's Every Day Gets a Little Closer (Basic Books 1974), where you can read Yalom and the client Elkin's.journals during the course of a lengthy therapy.

\section{Selecting Clients.}

Choose clients for the project who you think will be good at putting their thoughts into writing and who like writing. They need to be clients who want to reflect. Some clients write journals of their own accord and consider this fun. The more a client can describe his/her experiences concretely, the more we can learn. Clients become co-researchers in their use of therapy and their lives. You have to consider whether the project might interest the client before you ask them. The client can choose to participate in the project - they can also choose to stop during the project if they feel like it.

The method can also 'kick start' the therapy, as the journal method sets the client off considering their life. So the method is particularly suited to clients, who want things to 'get going' quickly.

There is a set of guidelines for the clients. This guidelines contain details that are not included here, so please acquaint yourself with them, so you can help clients with any questions they may have. If you or your client have any questions, mail or call me. Don't hold yourself back.

Please support your client in their participation in the project during the course of the project. You can do this by, for example, during some of the sessions asking as follows:

'How's the writing going?'

'What do you think about the checklist - can you follow it'

'Do you have the checklist in front of you when you write? I would recommend it'

'It's important for the project that you try and follow the guidelines.' 
'If you cannot follow the guidelines, what makes this difficult?'.

\section{Your Journal.}

After each session answer the following questions.

A) What did you find significant in the session today?

Give each significant thing a number (1,2,3,etc). Describe everything you found significant for you and your client as concretely and with in much detail as possible. Remember - nothing is too trivial for the journal. Something significant may be concealed in something you consider trivial. Often new findings lie in small details. This is the strength of qualitative research.

B) How do you think these significant things played a part in the client's life outside therapy?

Go through each significant thing, one by one, and write your reflections down about how you think these significant things might have played party in your client's life outside therapy. Remember no thought is too trivial. Just write everything your think. If you cannot see why something might be significant for your client's life. Just write this down. Use the same numbers as before (1a, 2a, 3a, etc.) so I can follow which significant thing you are considering. I know you cannot predict how the sessions are significant for clients' lives outside therapy, but I would like to hear your thoughts nevertheless.

At the eleventh session you exchange journals with the client and during the following $1 \frac{1 / 2}{2}$ hour session you have the opportunity of discussing the experience with each other.

If you at some time, other than the set journal writing-time, think of something that might be significant for the journal, you are welcome to add this to the journal with a date of entry.

\section{The Twelfth Session.}

The agenda for the twelfth session is flexible.

Give each other personal feedback about what reading the other's journal was like. Give the client a personal response on aspects of his/her journal, which you find important or aspects where the client requests a response. Make sure you get a response from the client about what you wrote. Experience has shown that reading what you have thought about the client may be quite an experience for the client. If there are misunderstandings or things that need to be cleared up - do so.

Discuss the following question together.

How do you think the sessions played a part in the client's life outside therapy?

\section{Finally}

Hand your journals over to Thomas in WORD format together with the recordings of the sessions (1-10 $+12)$. 
Thomas will give you both pseudonyms and make sure you are not recognised. Thomas will continue to change the texts until you feel sure your identity is concealed. The recordings will be used to see what you are referring to in your journal, when this is necessary. They will not be transcribed.

Thomas will then ask for your written permission to publish the material and use the material in its anonymised form in reports and articles. He may also write a book.

Thomas may later want to interview you. The content of such an interview would be confidential.

\title{
Organising your writing.
}

Experience has shown that it is important to take a short break after the session, and before you write. When you write, make sure there is peace and quiet - don't answer the phone or mails. Consider your journal writing time as your would a session with a client. Give yourself an hour at least.

\section{Response from the Researcher}

At some point there will be a response from the research project to TUBA - perhaps as a seminar for therapists on staff days. Written material will also be produced. It is hard to say anything now about the form this response will take. If the clients are interested they will also be able to read a final report/dissertation. The material will be used as a research dissertation and in articles in English. Copies of these will be made available to you.

If you have any questions - don't hesitate to call or mail me.

\section{Thomas Mackrill Phone number Email address.}

\section{Method Checklist.}

\author{
Please write in Word format.
}

Remember to write both the date when you are writing and the date of the session you are referring to.

\section{After each session (preferably within 48 hours)}

Answer the following questions and write in as much detail as possible.

A) What did you find significant in the session?

\section{Describe everything you found significant in as much detail as possible.}

Give each significant thing a number (1,2,3,etc). Please write a lot. Write whatever you consider important for you or your client down. Describe everything you found significant for you and your client as concretely and with as much detail as possible. Remember - nothing is too trivial for the journal. Something significant may be concealed in something you consider trivial. Often new research findings are concealed in small details. This is the strength of qualitative research. 
Answer the following question.

B) How do you think these significant things played a part in the client's life outside therapy?

Go through each significant thing one by one and write your reflections down about how you think these significant things might have played party in your client's life outside therapy. Use the same numbers as before (1a, 2a, 3a, etc.) so I can follow which significant thing you are considering. Remember no thought is too trivial. Just write everything your think. If you cannot see why something might be significant for your client's life - just write this down. Obviously, you cannot predict how the sessions significant for clients lives outside therapy, but your thoughts are important for the project nevertheless.

\section{After you have written, assess what you have written.}

Re. a). Ask your self. Have I described the significant things precisely enough, so Thomas will be able to grasp what I found significant?

Re. b) Could I write more about how this incident played a part in my client's life outside therapy? Do I hope the client will think differently about her/himself, others or the world? Or do I hope the client will experience the world in a different way or participate in the world in a different way? If so how? 